\title{
X-ray spectral analysis of sintered articles made of electroerosive lead bronze obtained in lighting kerosene
}

\author{
E.V. Ageev, A.S. Pereverzev", and B.N. Sabel'nikov \\ Southwest State University, 305040 Kursk, Russian Federation
}

\begin{abstract}
The article presents the results of X-ray spectral analysis of sintered products made of electroerosive materials of the BrS30 alloy obtained in lighting kerosene. It is shown that during uniaxial pressing and sintering in an argon atmosphere of electroerosive materials of the BrS30 alloy, the main elements on the surface of sintered products are carbon, copper, and lead.
\end{abstract}

\section{Introduction}

Bronze is widely used in modern mechanical engineering, rocketry, aviation, shipbuilding and other industries. Due to their resistance to mechanical abrasion and high corrosion resistance, bronze products are used for the manufacture of machine parts and devices that participate in moving units in the friction process.

Lead bronze has excellent antifriction properties, withstands shock loads well, and is also characterized by high strength and refractoriness.

Recently, bronzes have been widely used as components of powder antifriction materials or thin-walled porous coatings impregnated with solid lubricants [1].

To develop technologies for the practical application of powder materials obtained from lead bronze waste and to assess the effectiveness of their use, it is necessary to carry out comprehensive theoretical and experimental studies.

The aim of the work was to carry out X-ray spectral analysis of sintered samples from electroerosive materials of BrS30 alloy obtained in lighting kerosene.

\section{Materials and Methods}

For the implementation of the planned studies, waste of lead bronze grade BrS30 (GOST 493-79) was selected. Lighting kerosene is used as a working fluid. To obtain dispersed powder on an experimental setup [2], the waste was subjected to electroerosive dispersion.

The following electrical parameters of the installation were used:

- pulse repetition rate $95 \ldots 105 \mathrm{~Hz}$;

- voltage across the electrodes $190 \ldots 200 \mathrm{~V}$;

\footnotetext{
* Corresponding author: chaser-93@yandex.ru
} 
- the capacity of the capacitors is $65.5 \mu \mathrm{F}$.

As a result of the local impact of short-term electrical discharges between the electrodes, the waste material was destroyed with the formation of dispersed powder particles [3-19] (Fig.1).

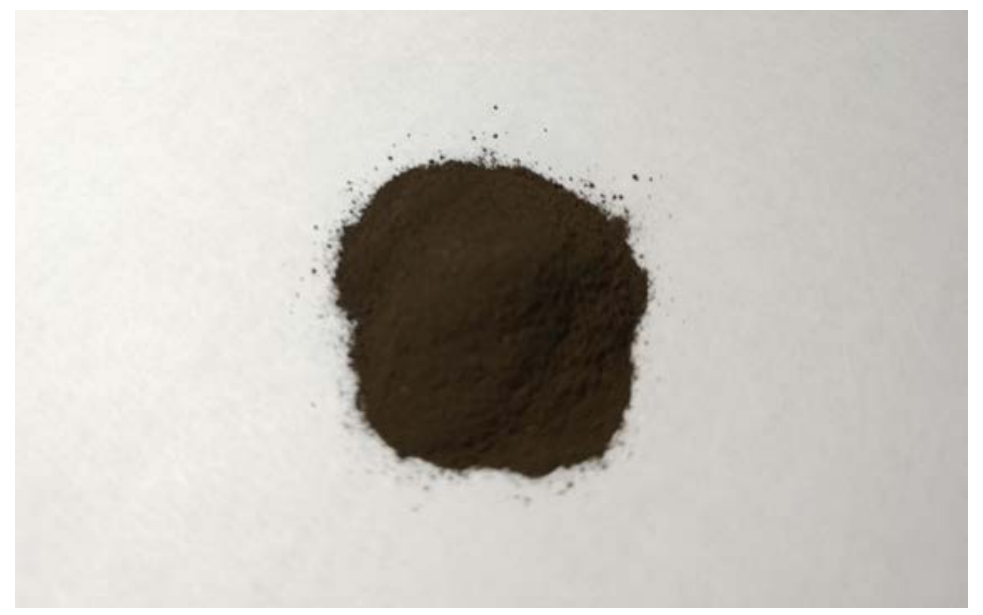

Fig. 1. Lead bronze EDM materials

To obtain the compacted materials, a HERZOG TP20 hydraulic table press for manual tablet compression was used. The pressing was carried out in a steel mold with a diameter of $10 \mathrm{~mm}$, at a pressure of $1500 \mathrm{MPa}$, holding under a pressure of 2 minutes. Then, the compacted samples were sintered in a Nabertherm RS 80/300/13 / P470 folding tube furnace for 12 hours at a temperature of $827^{\circ} \mathrm{C}(1100 \mathrm{~K})$ in an argon atmosphere.

Using an EDAX energy-dispersive X-ray analyzer built into a QUANTA 200 3D scanning electron microscope (Fig. 2), characteristic X-ray spectra were obtained at different points on the sample surface. X-ray spectral microanalysis is understood as the determination of the elemental composition of micro-objects from the characteristic X-ray radiation excited in them.

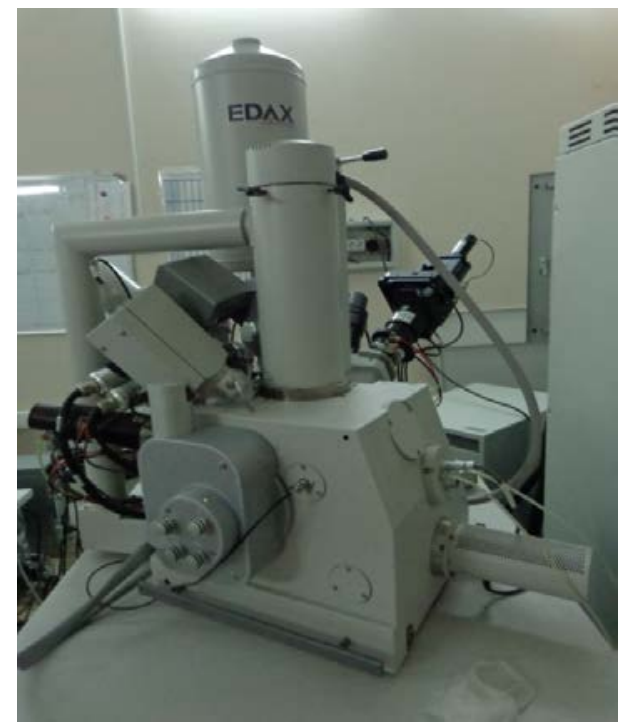

Fig. 2. Scanning electron microscope QUANTA 200 3D 


\section{Results}

On the presented spectrogram, a certain chemical element corresponds to each peak of a certain height (Fig. 3).

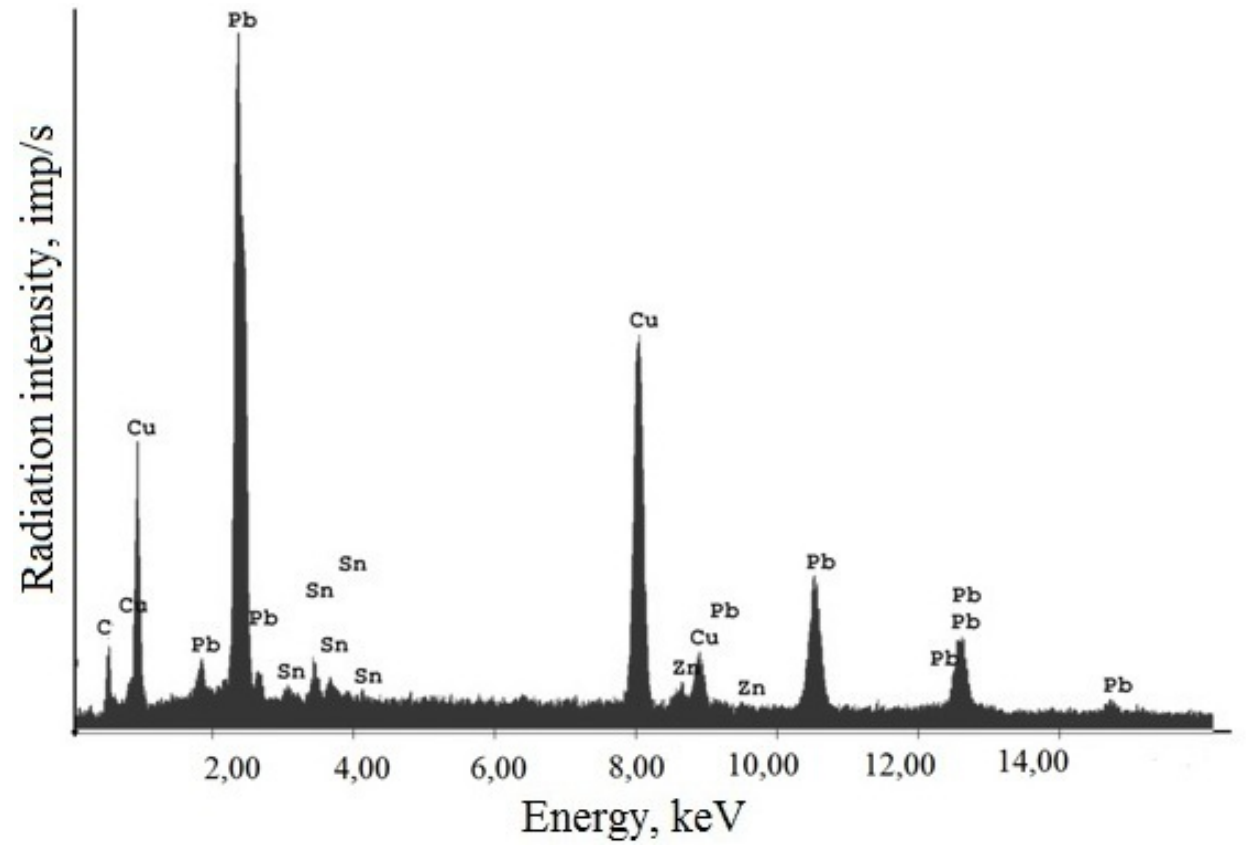

Fig. 3. Spectrogram of the surface of the sintered samples

The elemental composition obtained as a result of X-ray spectral microanalysis is presented in Table 1.

Table 1. Elemental composition of the studied samples

\begin{tabular}{|c|c|c|}
\hline Element & Mass fraction, $\%$ & Atomic fraction, $\%$ \\
\hline $\mathrm{C}$ & 5,48 & 28,99 \\
\hline $\mathrm{Sn}$ & 3,55 & 2,54 \\
\hline $\mathrm{Cu}$ & 31,75 & 42,33 \\
\hline $\mathrm{Zn}$ & 2,17 & 2,81 \\
\hline $\mathrm{Pb}$ & 57,05 & 23,33 \\
\hline Total & 100,00 & 100,00 \\
\hline
\end{tabular}

According to the presented data, it was found that the main elements in a sintered sample of lead bronze electroerosive materials obtained in kerosene are carbon, copper, and lead. The rest of the elements are distributed relatively evenly.

\section{Conclusion}

X-ray microanalysis made it possible to determine the elemental composition of the sintered samples. Based on the results of the presented data, it was established that the main elements in a sintered sample of lead bronze electroerosive materials obtained in kerosene are carbon, copper, lead. The rest of the elements are distributed relatively evenly. The presence of free carbon on the surface is explained by the fact that the electroerosive 
materials were obtained in a carbon-containing liquid - lighting kerosene. The conducted research will determine the most relevant area of application of the samples obtained and will improve the quality of scientific and technical developments.

The reported study was funded by RFBR, project number 19-38-90039.

\section{References}

1. A.A. Lipatov, Reactive diffusion in cutting high-alloy steel by means of a hard-alloy tool, Russian Engineering Research, 2013, vol. 33, No. 3, pp. 144-149.

2. E.V. Ageev, The patent 2449859, the Russian Federation, C2, B22F9/14. No 2010104316/02; appl. 08.02.2010; publ. 10.05.2012. - 4 p.

3. V.L. Bibik, Forecasting of hard-alloyed cutting tool resistance based on thermal diffusivity, Materials Science Forum, 2013, vol. 762, pp. 777-781.

4. E.V. Azarova, E.A. Levashov, V.G. Ralchenko, A.P. Bolshakov, E.E. Ashkinazi, Creation of strong adhesive diamond coatings on hard alloy by electric-spark alloying, Metallurgist, 2010, vol. 54, № 7-8, pp. 523-529.

5. Z. Qiao, X. Ma, W. Zhao, H. Tang, B. Zhao, Nanostructured novel cemented hard alloy obtained by mechanical alloying and hot-pressing sintering and its applications, Journal of Alloys and Compounds. 2008. vol. 462. No. 1-2. pp. 416-420.

6. K. Maruyama, T. Nonaka, H.Y. Kim, Effects of $\alpha 2$ spacing on creep deformation characteristics of hard oriented pst crystals of tial alloy, Intermetallics, 2005, vol. 13, No. 10, pp. 1116-1121.

7. E.V. Ageev, E.V. Ageeva // Bulletin of mechanical engineering. - (2013) 11. 51-57.

8. E. V. Ageev, B. A. Semenikhin, R. A. Latypov, Method for producing nanostructured powders based on the WC-CO system and device for its application, Fund. Prikl. Probl. Tekhn. Tekhnolog, v. 5, pp. 39-42 (2010)

9. Oskolkova T.N., Budovskikh E.A., Electric explosion alloying of the surface of hard alloy vkloks with titanium and silicon carbide, Metal. Sci. Heat Treat, v. 55, pp. 96-99 (2013)

10. Karlsson J., Snis A., Engqvist H., Lausmaa J., Characterization and comparison of materials produced by Electron Beam Melting (EBM) of two different Ti-6Al-4V powder fractions, Journal of Materials Processing Technology, v. 213, pp. 2109-2118 (2013)

11. Gu D.D., Meiners W., Wissenbach K., Poprawe R., Laser additive manufacturing of metallic components: materials, processes and mechanisms, International Materials Reviews, v. 57, pp. 133-164 (2012)

12. N. Radek, Determining the operational properties of steel beaters after electrospark deposition, Maintenance and Reliability, v. 4, pp. 10-16 (2009)

13. A.V. Ribalko, O. Sahin, The use of bipolar current pulses in electro spark alloying of metal surfaces, Surface \& Coatings Technology, v. 168, pp. 129-135 (2003)

14. Z. Chen, Y. Zhou, Surface modification of resistance welding electrode by electrospark deposited composite coatings: Part I. Coating characterization., Surface \& Coatings Technology, v. 201, pp. 1503-1510 (2006)

15. I.V. Galinov, R.B. Luban, Mass transfer trends during electrospark alloying, Surface \& Coatings Technology. v. 79, pp. 9-18 (1996)

16. Azarova E.V., Levashov E.A., Ralchenko V.G., Creation of strong adhesive diamond coatings on hard alloy by electric-spark alloying, Translated from Metallurg. v. 8, pp. 50-55 (2010) 
17. A. Pereverzev., E. Ageev., X-ray diffraction analysis of products sintered from isostatically pressed leaded bronze powders, MATEC Web of Conferences 298, 00037 (2019)

18. E.V. Ageev, S.V. Khardikov, E.A. Vorobyev, A.A. Sysoev, Shape and morphology of the particles surface of electroerosive powders of micro- and nanometric fractions, obtained from H17MYuA steel in kerosene, MATEC Web of Conferences 298, 00127 (2019)

19. R.A. Latypov, E.V. Ageeva, G.R. Latypova, X-ray microanalysis of powders, obtained by electroerosion dispersion of the alloy W-Ni-Fe, MATEC Web of Conferences 298, 00125 (2019) 